International Journal of Pure and Applied Mathematics

Volume 106 No. $4 \quad 2016,1029-1036$

ISSN: 1311-8080 (printed version); ISSN: 1314-3395 (on-line version)

url: http://www.ijpam.eu

doi: 10.12732/ijpam.v106i4.5

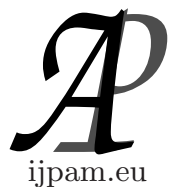

\title{
ON A DIVIDEND-PAYING STOCK OPTIONS PRICING MODEL (SOPM) USING CONSTANT ELASTICITY OF VARIANCE STOCHASTIC DYNAMICS
}

\author{
S.O. Edeki ${ }^{1}$, O.O. Ugbebor ${ }^{2}$, E.A. Owoloko ${ }^{3}$ \\ ${ }^{1,3}$ Department of Mathematics \\ Covenant University \\ Canaanland, Otta, NIGERIA \\ ${ }^{2,3}$ Department of Mathematics \\ University of Ibadan \\ Ibadan, NIGERIA
}

\begin{abstract}
In this paper, we propose a pricing model for stock option valuation. The model is derived from the classical Black-Scholes option pricing equation via the application of the constant elasticity of variance (CEV) model with dividend yield. This modifies the BlackScholes equation by incorporating a non-constant volatility power function of the underlying stock price, and a dividend yield parameter.
\end{abstract}

AMS Subject Classification: 91B25, 37N40, 35R60

Key Words: stock options, CEV, stochastic dynamics, dividend yield

\section{Introduction}

In financial mathematics, option pricing theory is a core aspect requiring frequent attention of financial analysts and financial engineers, actuaries and so on [1-3]. In recent years, ever since the 1987 market crash, several market observations have revealed the association between stock price and volatility; leverage effect is the phenomenon behind this [4]. The effect as explained in [4] states that "if a firm's stock price falls, it will increase the debt-equity ratio of

Received: January 2, 2016

Published: April 1, 2016

${ }^{\S}$ Correspondence author (c) 2016 Academic Publications, Ltd.

url: www.acadpubl.eu 
the firm and therefore increases the variance of the stock's return" It is worth mentioning that the Black-Scholes option pricing formula [5] does not reconcile this leverage effect parameter.

Black in [6], considered this financial leverage effect. This was later extended and supported by other researchers in terms of empirical evidences [7]. Consequently, a theoretical framework to capture this relationship (inverse) between the stock price and its variance is built by Constant Elasticity of Variance $(\mathrm{CEV})$ class of stock price distributions.

In option pricing theory, Black and Scholes assumed that the underlying stock price process, $S_{t}$, follows a lognormal distribution and solves the Stochastic Differential Equation (SDE):

$$
d S_{t}=\mu S_{t} d t+\sigma S_{t} d W_{t},
$$

where $\mu$ represents rate of return (drift coefficient), $\sigma$ the stock price volatility rate, and $W_{t}$ is a standard Brownian motion.

The basic assumptions of the Black-Scholes model include arbitrage-free opportunities, no dividend paying equity, constant risk-free-rate, constant volatility, and so on $[8,9]$. In this work, emphasis will be on how to address the assumptions of no dividend yield and that of constant volatility (stock price standard deviation). The assumption of the volatility being constant was to keep the model linear and for analytical solvability. However, in practical settings, constant volatility is not realistic. We shall therefore resort to the following form of SDE in the next subsection to modify the Black-Scholes model for stock option valuation.

\section{A Note on CEV Option Pricing Model (CEVOPM)}

The assumption of the constant volatility parameter in the Black-Scholes model has drawn the attention of many researchers even in terms of the analytical or numerical solutions obtained via the different modifications of the Black-Scholes model [10-12] and the references therein. Delbean and Shirakawa proved that arbitrage opportunities are allowed in the CEV model when the stock price is on strictly positive conditions [13].

Cox and Ross [14] considered the CEV diffusion process governed by the SDE when $q=0$ :

$$
d S_{t}=S_{t}(\mu-q) d t+\sigma S_{t}^{\frac{\xi}{2}} d\left(W_{t}\right),
$$

whose solution at time $t$ is $S_{t}=S, \xi$ denotes an elasticity rate, $q$ is a dividend yield parameter, while $\mu, \sigma$, and $W_{t}$ remain as defined in the earlier section. The 
elasticity rate parameter $\xi$, which is the central feature of the model, controls the relationship between the volatility and price of the underlying asset.

The CEV diffusion model seems to be a natural extension of the Geometric Brownian Motion (GBM). In [15], Beckners considered the CEV and its implications for option pricing on the basis of empirical studies and concluded that the CEV class could be a better descriptor of the actual stock price, in terms of behavior than the traditionally used lognormal model. Xiao et al. [16], applied the CEV model for the study of a defined-contribution pension plan where benefits are paid by annuity; with a focus on the model describing the dynamic movements of the risky market price.

In what follows, the Black-Scholes model will be modified using the SDE associated with the CEV model in (2).

\subsection{The Modified Black-Scholes Model Derivation (CEV-B-S Model)}

Let $S_{t}$ be the stock price at time $t$, satisfying the SDE in (4), such that the value of the contingent claim is $V=V(S, t)$ with $V \in C^{2,1}(R \times[0, T])$, so by applying Ito lemma, we have:

$$
\begin{aligned}
& d V=\frac{\partial V}{\partial t} d t+\frac{\partial V}{\partial S} d S+\frac{1}{2} \frac{\partial^{2} V}{\partial S^{2}}\langle d S\rangle \\
& =\frac{\partial V}{\partial t} d t+\frac{\partial V}{\partial S}\left(S_{t}(\mu-q) d t+\sigma S_{t}^{\frac{\xi}{2}} d\left(W_{t}\right)\right) \\
& +\frac{1}{2} \frac{\partial^{2} V}{\partial S^{2}}\left\langle S_{t}(\mu-q) d t+\sigma S_{t}^{\frac{\xi}{2}} d\left(W_{t}\right)\right\rangle .
\end{aligned}
$$

But

$$
\left\langle S_{t}(\mu-q) d t+\sigma S_{t}^{\frac{\xi}{2}} d\left(W_{t}\right)\right\rangle=\sigma^{2} S_{t}^{\xi} d t
$$

where

$$
\Theta \bullet d W_{t}=\left\{\begin{array}{l}
d t, \text { for } \Theta=d W_{t} \\
0, \quad \text { otherwise }
\end{array}\right.
$$

Hence, (3) becomes:

$$
d V=\frac{\partial V}{\partial t} d t+\frac{\partial V}{\partial S}\left(S_{t}(\mu-q) d t+\sigma S_{t}^{\frac{\xi}{2}} d\left(W_{t}\right)\right)+\frac{1}{2} \frac{\partial^{2} V}{\partial S^{2}}\left(\sigma^{2} S_{t}^{\xi} d t\right)
$$

Therefore

$$
d V=\left(\frac{\partial V}{\partial t}+(\mu-q) S \frac{\partial V}{\partial S}+\frac{1}{2} \sigma^{2} S^{\xi} \frac{\partial^{2} V}{\partial S^{2}}\right) d t+\sigma S^{\frac{\xi}{2}} \frac{\partial V}{\partial S} d W
$$


Suppose $\Xi(t)$ is a delta-hedge-portfolio constructed by longing a contingent claim, and shorting a delta unit of the concerned underlying asset such that:

$$
\begin{aligned}
\Xi(t) & =-\Delta S+V(S, t), \\
d \Xi(t) & =d V(s, t)-\Delta d S, \\
\Delta & =\frac{\partial V}{\partial S}, \text { and } \\
d \Xi(t) & =r \Xi(t) d t .
\end{aligned}
$$

In a bid to making the portfolio value riskless, (say bank account), where $r$ is a riskless rate, we therefore have:

$$
\begin{gathered}
d \Xi(t)=d V(S, t)-\Delta d S, \\
d \Xi(t)=\left(\frac{\partial V}{\partial t}+(\mu-q) S \frac{\partial V}{\partial S}+\frac{1}{2} \sigma^{2} S^{\xi} \frac{\partial^{2} V}{\partial S^{2}}\right) d t+\sigma S^{\frac{\xi}{2}} \frac{\partial V}{\partial S} d W \\
-\Delta\left((\mu-q) S d t+\sigma S^{\frac{\xi}{2}} d W\right), \\
\Rightarrow \quad \frac{d \Xi}{d t}=\left(\frac{\partial V}{\partial t}+(\mu-q) S \frac{\partial V}{\partial S}+\frac{1}{2} \sigma^{2} S^{\xi} \frac{\partial^{2} V}{\partial S^{2}}\right) \\
+\sigma S^{\frac{\xi}{2}} \frac{\partial V}{\partial S} \frac{d W}{d t}-\frac{\partial V}{\partial S}\left((\mu-q) S d t+\sigma S^{\frac{\xi}{2}} d \frac{d W}{d t}\right) .
\end{gathered}
$$

Thus:

$$
\frac{d \Xi}{d t}=\frac{\partial V}{\partial t}+\frac{1}{2} \sigma^{2} S^{\xi} \frac{\partial^{2} V}{\partial S^{2}} \equiv r \Xi
$$

So, combining (7), (8) and (11), we obtain

$$
\frac{\partial V}{\partial t}+r S \frac{\partial V}{\partial S}+\frac{1}{2} \sigma^{2} S^{\xi} \frac{\partial^{2} V}{\partial S^{2}}-r V=0
$$

Equation (12) is referred to as the modified Black-Scholes model via CEV SDE with dividend yield.

\section{Discussion of Result}

When $\xi=2$, (12) becomes the classical Black-Scholes model. It is also observed that (12) coincides with the model obtained when the stock price $S_{t}$ follows the SDE in (2) without a dividend yield [17], but the difference(s) between the stock prices $S_{N D}$ and $S_{D}$ for the SDEs in (2) will be highlighted in the next subsection. 


\subsection{Comparison of the SDE Models}

In what follows, we shall compare the fundamental features of the associated models presented above in this subsection.

Let $S_{N D}$ and $S_{D}$ be the solutions of the SDE in (2), indicating no dividend and dividend yields respectively. Suppose further that $V_{0}^{B S M}$ denotes the volatility of the Black-Scholes model, $V_{0}^{C E V M}$ is the volatility of the CEV model without dividend yield, $V_{0 D}^{C E V M}$ is the volatility of the CEV model with dividend yield, $V_{B S M}^{a r}$ the variance of the Black-Scholes model, $V_{C E V M}^{a r}$ the variance of the CEV model without dividend yield, $V_{C E V M}^{a r D}$ the variance of the $\mathrm{CEV}$ model with dividend yield. Then, the following are thus deduced easily:

For volatilities: $\quad V_{0}^{B S M}=\sigma, V_{0}^{C E V M}=\sigma S^{\frac{\xi}{2}-1}, V_{0 D}^{C E V M}=\sigma_{*} S_{D}^{\frac{\xi}{2}-1}$

For variances: $V_{B S M}^{a r}=\sigma^{2}, V_{C E V M}^{a r}=\sigma^{2} S^{\xi-2}, V_{C E V M}^{a r D}=\sigma_{*}^{2} S_{D}^{\xi-2}$

For mean parameters: $\quad \bar{m}_{C E V M}^{N D}=\mu, \quad \bar{m}_{C E V M}^{D}=\mu-q$

Note: In both cases of the governing SDEs: with or without dividend parameter, it is clear that the variances $V_{0 D}^{C E V M}=g\left(\sigma, S_{D}\right)$ and $V_{0 D}^{C E V M}=$ $h\left(\sigma, S_{N D}\right)$ are functions of the underlying asset prices $S_{N D}$ and $S_{D}$ respectively.

\subsection{Interpretation of Results}

We present a graph (see Figure 1) below to show the estimates of the distribution of $(S(T)-1,0)^{+}$using different values of the elasticity parameter for results interpretation, and to show the economic implications of the elasticity rate. For the purpose of simulation, we consider the following values for the concerned parameters: $T=2.0, \sigma=0.3, \mu=0.05$ and for $\xi=0.1 \xi=2$, and $\xi=5$ See [17] and the related references therein for details.

\subsection{Elasticity and Elasticity Parameter}

The following relationship is used in the computation of elasticity [17]:

$$
e=\left(\frac{d V_{r}^{C E V M}}{d S}\right) \div\left(\frac{V_{r}^{C E V M}}{d S}\right)
$$

while

$$
\frac{d V_{r}^{C E V M}}{d S}=(\xi-2) \sigma^{2} S^{\xi-3} \quad \text { and } \quad V_{r}^{C E V M}=\sigma^{2} S^{\xi-2}
$$




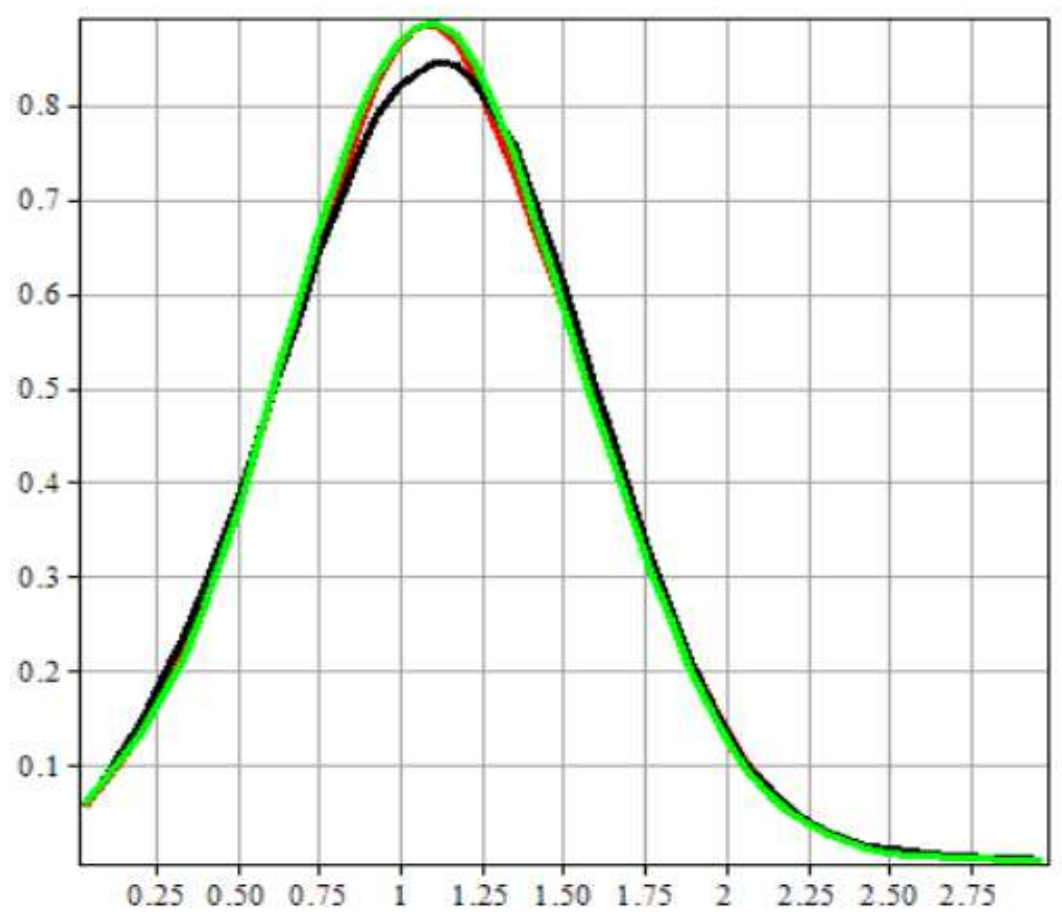

Figure 1: Estimates of the distribution

SO

$$
e=\xi-2 .
$$

Note. It is obvious from (13) that for any positive constant $k$ with little algebra, we have:

$$
S_{t}^{e}=k V_{r}^{C E V M} .
$$

\section{Remarks.}

1. Elasticity is said to be zero if $\xi=2$; therefore, the stock price is lognormally distributed as indicated in the classical Black-Scholes model.

2. Elasticity is -1 as proposed by Cox and Ross (see [14]), if $\xi=1$.

3. When $\xi<2$, the so-called leverage effect observed mainly in equity market, shows that the stock volatility increases as the corresponding price falls. 
4. On the other hand, when $\xi>2$, the so-called leverage effect observed mainly in commodity market, indicates that the volatility of the commodity increases as the corresponding price increases

The relationship between the stock price and the volatility of its return has been shown empirically to be negative see $[18, \mathrm{pg} 6]$. This is guaranteed when $\xi<2$ is considered.

\section{Concluding Remarks}

In this paper, we proposed a pricing model for stock option valuation. The model is derived as a modification of the classical Black-Scholes pricing model using the constant elasticity of variance model with the incorporation of dividend yield parameter. This serves as an alternative to the traditional lognormal model for stock prices. In CEV model, the price variations of the underlying asset are negatively correlated with variations in the level of volatility; this helps in reducing the known volatility smile effects of the lognormal model. As a modification of the Black-Scholes pricing model, a non-constant volatility power function is introduced, and comparison between the CEV models with or without dividend yield is made.

\section{Acknowledgments and Comments}

The authors are indeed grateful to Covenant University for financial support and provision of good working resources. We also thank the anonymous referee(s) for their valuable time, constructive and helpful comments geared towards improving this paper.

This work was carried out in collaboration by the concerned authors: SOE, OOU and EAO; with positive contribution. They all read and approved the final manuscript for publication.

\section{References}

[1] O.O. Ugbebor and S.O. Edeki, "On Duality Principle in Exponentially Levy Market", Journal of Applied Mathematics \& Bioinformatics, 3 (2), (2013), 159-170.

[2] A. Habib, "The calculus of finance", Universities Press (India) Private Ltd., (2011).

[3] S.O. Edeki, I. Adinya, O.O. Ugbebor, "The Effect of Stochastic Capital Reserve on Actuarial Risk Analysis via an Integro-differential equation", IAENG International Journal of Applied Mathematics, 44 (2), (2014): 83-90. 
[4] N. Wang, "Price sensitivity to the exponent in the CEV model", U.U.D.M. Project report, Uppsala Universitet, (2012).

[5] F. Black, M. Scholes, "The pricing of options and corporate liabilities", J. Pol. Econ. 81 (1973): 637-659.

[6] F. Black, "Studies of stock price volatility changes", Proceedings of Meetings of the American Statistical Association, Business and Economics Statistics Division, (1976).

[7] R. Schmalensee, R. Trippi, "Common stock volatility expectations implied by option premia" Journal of finance, (1978).

[8] E.A. Owoloko and M.C. Okeke, "Investigating the Imperfection of the B-S Model: A Case Study of an Emerging Stock Market", British Journal of Applied Science 85 Technology 4 (29) (2014): 4191-4200.

[9] M. E. Adeosun, S. O. Edeki, O. O. Ugbebor, "Stochastic Analysis of Stock Market Price Models: A Case Study of the Nigerian Stock Exchange (NSE)", WSEAS Transactions on Mathematics, 14, (2015): 353-363.

[10] J.D. Macbeth and L.J. Merville. "An empirical examination of the Black-Scholes call option pricing model", Journal of Finance, 34, (1979): 1173-1186.

[11] S.O. Edeki, O.O. Ugbebor, E.A. Owoloko, Analytical Solutions of the Black-Scholes Pricing Model for European Option Valuation via a Projected Differential Transformation Method, Entropy, 17 (11), (2015): 7510-7521.

[12] B. Lauterbach and P. Schultz, "Pricing warrants: an empirical study of the Black-Scholes model and its alternatives", Journal of Finance, 45 (1990.), p. 1181.

[13] F. Delbaen and H. Shirakawa, "A note of option pricing for constant elasticity of variance model", Asia-Pacific Financial Markets, 9 (2), (2002): 85-99.

[14] J. Cox and S. Ross, "The valuation of options for alternative stochastic processes", Journal of Financial Economics, 3, (1976): 145-166.

[15] S. Beckers, "The Constant Elasticity of Variance Model and Its Implications for Option Pricing", The Journal of Finance, 35, (3) (1980): 661-673.

[16] J. Xiao, Z. Hong, C. Qin, "The constant elasticity of variance (CEV) model and the Legendre transform-dual solution for annuity contracts" Insurance: Mathematics and Economics, 40, (2007): 302-310.

[17] S.O. Edeki, E.A. Owoloko, O.O. Ugbebor, "The Modified Black-Scholes Model via Constant Elasticity of Variance for Stock Options Valuation", AIP Conference proceedings, 1705, 020041 (2016); doi: 10.1063/1.4940289.

[18] Y. L. Hsu, T. I. Lin, and C. F. Lee, "Constant elasticity of variance (CEV) option pricing model: Integration and detailed derivation", Math. Comput. Simulation, 79 (2008), 60-71. 